\title{
1. Introduction to Human Capital Policy
}

\author{
David Neumark, Yong-seong Kim and \\ Sang-Hyop Lee
}

Education is a subject of never-ending public attention, and that attention has contributed to numerous reforms. One starting point in the search for better human capital policy is a careful review of past accomplishments and shortcomings of the education system, as well as future challenges facing it. Moreover, for most people the goals of human capital policy encompass the efficiency and effectiveness of policy, as well as its contribution to equity and social and economic mobility. The topics of this volume therefore delve into the quality of education, the effectiveness of public school systems and means of improving them, the competitiveness and accountability of higher education, and linkages between education and labor market outcomes.

The authors focus on Korea and the United States. The Korean education system can be credited for much of the remarkable economic growth achieved by the country in recent decades, during its transformation into an industrialized country. The economy during this period is regarded as a textbook case of taking a leap from being a marginal player in the global economy to being a leading one. Many factors must be taken into account to explain this transition. Among them, the country's education system, well designed and effective for its time, played an essential role in achieving both industrialization and social mobility. In terms of the quantity and quality of its human capital, Korea has made astonishing progress since regaining its independence in the late 1940s. With the rapid expansion of enrollment in both primary and secondary schools, the literacy rate increased from about 20 percent in 1945 to almost 100 percent today. The proportion of the population with tertiary education is the highest among the Organisation for Economic Co-operation and Development (OECD) countries. The expansion of education was accompanied by a soaring academic record. Recent international achievement tests, such as the OECD's Program for International Student Assessment 
(PISA), have ranked Korea at the top in mathematics, reading and sciences.

As Korea moves to a knowledge-based society and a more creative economy, however, human capital policy must be reconsidered. Recent declines in the rate of economic growth, and deterioration in labor market conditions, suggest that upgrading the education system may be critical to sustaining strong performance of the Korean economy in the longer run. A number of features of the Korean education system create potential challenges.

Stressful competition to enter universities, and intensive focus on test scores, have resulted in doubts about the quality of education received in public schools, which in turn has caused the proliferation of private tutoring and consequently a heavy economic burden on the average family. Difficulties encountered in the transition from school to labor market, including the retraining programs for new recruits that businesses have to carry out, raise questions about the quality of human capital accumulated under the current education system. At the same time, there are signs of deterioration in students' motivation, creativity, interpersonal communicative and cooperative attitudes, and other character skills. More foreboding for the future economy, the research and development (R\&D) capabilities of Korea's universities are generally rated well below those in advanced countries. There are also emerging challenges with regard to equity and mobility, as academic achievement appears to be increasingly affected by socioeconomic family background. Korean education, which used to promote mobility, is becoming a less effective means of doing so.

As this volume demonstrates, the issues surrounding education are wide-ranging in scope and highly complicated in nature. By comparing Korea's human capital policies with those in the United States, the authors examine issues relevant to understanding Korea's human capital policies in the past and draw out useful recommendations for new directions that may be needed. The chapters cover education reform in Korea, quality of education, the effectiveness of the public school system, competitiveness and accountability of higher education, the linkage between education and socioeconomic status, and labor market outcomes tied to human capital policies. This book also places Korea's experience in a broader international perspective by comparing Korea's case with Western countries. The comparative perspective broadens the evidence base on human capital policies, and may stimulate additional thinking and research by contrasting primarily Western experiences and perspectives on human capital policy with those of a newly industrialized economy in Asia. 


\section{EDUCATION REFORM ISSUES}

In Chapter 2, Hisam Kim shows that Korean society, once characterized by a high level of social mobility, faces decreasing optimism over the significance of efforts in moving up the socioeconomic ladder. He begins with very detailed analyses based on surveys of attitudes toward social mobility in Korea. These surveys, conducted at different points in time, generally show that: (1) pessimism about upward mobility in society has been increasing; (2) the correlation in socioeconomic status across generations has been increasing; and (3) the younger generation is skeptical about the role of education as a ladder of intergenerational upward mobility. Kim's analysis reveals two trends that reduce equity and mobility: first, that income inequality has been increasing over time; and second, that educational paths have become increasingly correlated with parental socioeconomic status.

The author then turns to possible policy remedies that may increase mobility, which include early intervention to prevent loss of talent and public support for vulnerable students to help them improve job market skills and social networks. Finally, Kim also suggests that opening multiple routes to success, other than a narrowly defined route (such as from select universities to good jobs), should be encouraged and supported. The last point implies that the role of education in social mobility in the future may need to be redefined away from a single ladder of upward movement in one-directional zero-sum competition for highly concentrated desires and toward multiple bridges to help individual students realize their own dreams.

\section{ISSUES IN HIGHER EDUCATION}

In Chapter 3, Jaehoon Kim discusses measures to enhance the competence and responsiveness of Korean universities in relation to socioeconomic needs. He begins with the competence measure of university education achievement in Korea. Although Korea routinely scores high marks in the OECD's Program for International Student Assessment (PISA), the author attributes this outcome not to the quality of the public primary and secondary education system but to the value-added from investment in after-school tutoring.

Korea has the world's highest university enrollment rate. On the other hand, its responsiveness to socioeconomic needs has lagged behind, and Korean universities do not compare well with their peers worldwide. An important turning point to increase the number of universities and so put universities in a more competitive environment was the institution of the 
qualification rule, adopted in 1996 and first applied in 1997, which allowed the establishment of new universities, on condition of meeting certain requirements. The new rule appeared to be a policy supposed to promote competition among universities, and thus to enhance the competence of universities and to reduce the involvement of the government in university affairs.

Kim analyzes data on Korean universities in order to examine their impacts and the possibility of adopting quasi-market competition. The empirical results for universities in the Seoul metropolitan area, even after the adoption of the principle of the qualification rule in 1996, reveal that their enrollment is still highly regulated, that the difficulties of gaining admission have greatly increased, and that university competence (as measured, for example, by the employment rates of graduates) is lower than that of nonmetropolitan universities without enrollment regulations. This situation suggests that one possible way to enhance the competence of universities overall and to make the higher educational market more competitive may be to offer financial incentives to encourage some universities in the metropolitan area to move to nonmetropolitan areas.

The 2013 Master Plan for the Development of Higher Education introduced a new university rating system and tied acceptance limits to these ratings. Given that government subsidies remain in place, however, the author speculates that the changes will do little to improve or eliminate underperforming universities. Since the rankings must have provided prospective students with information about university quality that was not previously available, why did some students continue to matriculate in the ones that received poor ratings?

In Chapter 4, Susan M. Dynarski discusses recent trends in student debt and policy prescriptions to improve the ways that higher education is financed in the United States (US). The author begins with a picture of student loans in the United States; one that is not as dire as many commentators have suggested. Indeed, contrary to many media reports, she argues that student debt is not out of control, and that although borrowing has risen over time, the typical US student holds debt that is well below the lifetime benefits of a college education. The typical student borrower is not under water, as were many homeowners during the mortgage crisis in 2008. In addition, while it is true that college tuition has risen dramatically over the past 20 years, many people do not pay the full cost. This may be desirable, as universities are engaging in a form of price discrimination, where different students pay different prices depending on their willingness or ability to pay. This is most likely efficient, and it may also expand access to higher education if richer students are subsidizing poorer students who otherwise could not afford college. 
The real issue is that there is a mismatch in the timing of the costs of college and the arrival of its benefits, with payments falling due when earnings are still low and at their most variable. Ironically, this mismatch is the very motivation for providing student loans in the first place. The author offers some possible solutions. One is an income-based repayment structure for student loans, with payments automatically flexing with earnings over a longer horizon than the ten years that are currently standard. While income-based repayment options do exist within the current system, few borrowers take them up; perhaps because of administrative barriers to accessing them. Furthermore, the existing options do not adjust loan payments quickly enough to respond to the high-frequency shocks that characterize young people's earnings, especially during a recession. The author concludes that a well-structured repayment program would help to cushion borrowers against both micro and macro shocks. With an interest rate that appropriately accounts for the government's borrowing and administrative costs, as well as the default risk, such a program could be self-sustaining. Designing it, however, requires detailed data on individual earnings and borrowing, which are currently unavailable to researchers; including those within the government itself. If loan policy is to be firmly grounded in research, this gap in the data needs to be closed.

In Chapter 5, Sungmin Han examines the relationships between student loans, academic performance and default risk. He also examines how academic performance and default risk differ for students who borrow through Korea's two largest sources of student loans: the General Student Loan (GSL) program and the Income Contingent Loan (ICL) program.

Student loans can have a positive impact on student performance. If no loans were available, college students would probably have to work to pay tuition fees, whereas with a loan, students can spend more time on their studies, thereby improving their academic achievement. Even so, there are differences between the two types of loan in Korea. The GSL program requires that students begin paying off the loan while they are still in school, though students can choose the level of payment and repayment period. Although the repayment amount and period are flexible, the recipients may still have to work if they have difficulty paying off their debts. In addition, since students receiving a loan start their careers with debts, there is a high probability of selecting any job regardless of job quality in order to pay off the debt early. The ICL program, in contrast, does not require payment until after students leave school. It can allow students to focus more on their studies. But this provision may have a different impact and a negative side to it, depending on the purpose of taking the loan. Moreover, if it serves as an incentive to delay repayment by deferring graduation, the repayment can become more problematic than in the case of GSL loans. 
As the author notes, empirical studies suggest that ICL recipients perform better than GSL recipients. In terms of default, however, the probability of delinquency is higher when loans cover both living expenses and tuition than when they cover tuition alone. These findings suggest that although the ICL program is more effective in reducing students' financial burden, the repayment system should be improved to minimize the negative impact. Han accepts, nonetheless, that a rapid shift from GSLs to ICLs may impose a financial burden on the government budget. Thus, a gradual change of student loan policy is required.

\section{HUMAN CAPITAL INPUTS AND OUTCOMES}

In Chapter 6, Flávio Cunha provides a theoretical model for examining the linkage between parents' information sets and human capital formation of children. He begins with a survey of the existing literature on inequality in investments in human capital during the first few years of a child's life. While there are several nonmutually exclusive explanations for the pattern between investments and family socioeconomic status, the focus of this chapter is parental information. The author builds a model in which maternal subjective beliefs about the technology of skill formation may be correlated with socioeconomic status. These beliefs partially determine maternal expectations about returns on human capital investments, which, in turn, determine investment choices. If markets are complete, and if mothers have low expectations about returns to investments, then mothers with low socioeconomic status will invest too little in their children.

The author then shows that the evidence is consistent with a model in which parents are subjectively rational. Although parents act to maximize a well-defined objective function, they lack information about the constraints that link parenting style and investments to child development. He then shows that empirical implications of the model have been validated in recent experiments that provide parents with information that is important for fostering child development. These findings provide useful guidance for the design of new policies for narrowing the human capital gap that opens up long before children reach school.

In Chapter 7, Julian R. Betts examines the rationale of charter schools and reviews the literature concerning their impact on student performance. He begins by describing charter schools as a test of the theory of school choice. Charter schools are now one of the most important and fastestgrowing forms of school choice in the United States. Charter schools provide a new form of competition by allowing private agents to organize and operate schools financed partly or fully with tax revenues. However, 
the author also takes note of some issues that apply to charter schools but not to competing public and private schools, such as restrictions imposed by school districts on their expansion, problems with funding and special regulations.

The literature suggests the following. First, charter schools often generate positive increases in completion rates for high school and subsequently college. Second, some national and regional organizations that manage charter schools are highly effective while others are not. Third, black students appear to gain more from attending charter schools than other students do. Fourth, charter schools in urban areas appear to outperform charter schools as a whole. Fifth, charters are more effective in improving test scores in math than in reading. Sixth, charter schools produce some positive behavioral outcomes such as fewer disciplinary episodes, reduced pregnancy rates and less likelihood of going to jail, but with mixed results on attendance. Seventh, there is little evidence that charter schools skim the best students from public schools and thus reduce student achievement in public schools.

All of these findings vary substantially across charter schools, though. Betts concludes that variation in measured charter school effectiveness likely represents variation in the quality of charter schools and alternative public schools. In doing so, he provides a sobering reminder of the difficulties facing researchers in clearly identifying the source of differences in student performance in different types of schools.

In Chapter 8, Yoonsoo Park examines the question of whether private schools provide better education than public schools do. The study makes use of a survey of autonomous private high schools in Korea. It begins with the long-standing academic debate among education policymakers and interest groups in Korea since the High School Equalization Act of 1974. Under that Act, private high schools were required to operate in a way very similar to public high schools. In 2010, the government partially deregulated the equalization policy by granting a certain level of autonomy to selected private high schools. These schools are called autonomous private high (APH) schools and are essentially the first truly private high schools in Korea since 1974.

The author contributes to both the economic literature and the education policy debate in Korea by examining the effectiveness of APH school attendance on educational outcomes of students. To isolate a causal effect of the APH schools, Park uses birth order of students as an instrumental variable for APH school attendance, under the assumptions that firstborn students have a higher chance of attending those schools than do their later-born peers, and that birth order does not affect educational outcomes of students directly, other than through parental educational 
investment decisions. Applying this idea to data tracing students who entered high schools in 2010 over a three-year period, he finds that the APH school attendance substantially improves levels of student satisfaction, in comparison with regular high schools. However, Park does not find any clear evidence that attending APH schools improves achievement test scores, which suggests that the large academic performance gaps observed between the APH school students and regular high school students are largely driven by sample selectivity.

\section{HUMAN CAPITAL AND THE LABOR MARKET}

In Chapter 9, Harry J. Holzer reviews the recent empirical evidence on human capital formation among disadvantaged youth and adults in the United States. He focuses on the skills and credentials that are well rewarded in the labor market, and the different means of attaining them. He begins with a literature review and lists the main culprits identified by empirical research. Disadvantaged students tend to face important liquidity constraints that prevent them from enrolling in or completing a college education. Conditional on enrolling in a college, disadvantaged students are also more likely to choose fields or majors that offer low returns in the labor market. Holzer suggests a range of policies to improve these outcomes, such as recruitment and admission policies that open high-ranking colleges and universities to more disadvantaged students, better academic and career counseling, reforms in financial aid and remediation practices, and state subsidies based at least partly on the academic and employment outcomes of their students.

The author also reviews a range of alternatives to college programs, including high-quality career and technical education, and work-based learning programs and sectoral training, which have great promise but need to be carefully scaled up (and evaluated) before they will reach their potential. Holzer argues for policies to encourage better integration of education and labor market programs and institutions, while making both more responsive to the job market. The author concludes with cautions, as there are likely to be many pitfalls in implementing the policies and practices suggested.

In Chapter 10, WooRam Park examines the effects of human capital on industrial structure and productivity among OECD countries. He begins with a review of literature on the impact of human capital on various outcomes pertaining to industrial structure and growth. The micro studies tend to provide a uniform picture: the majority establish a strong positive relation between years of schooling and eventual income. However, the 
effect of educational attainment at the macro level often appears to be much weaker. The chapter advances the macro-level literature by examining the heterogeneity in the effect of human capital on the growth of industries through technology intensity. In particular, the author argues that if human capital facilitates technology adoption, then an increase in human capital will mostly affect the growth of technology-intensive industries. Park tests this hypothesis by examining whether human capital increases the share of high-tech industries and lowers the share of low-tech industries in terms of value-added and employment in the manufacturing sector. In essence, he tests whether human capital accumulation increases the technology intensity of the manufacturing sector.

Park uses a dataset at the industry level from OECD countries, based on technological characteristics. He tries to overcome the limitations of the previous literature by using technology characteristics of industries that could be applied to most countries in the sample. Using these data, the study finds that educational attainment - regardless of the levels of educational attainment - does not increase the shares in terms of value-added and employment in the technology-intensive industries. This might imply that the technologies adopted by high-tech industries among developed countries are likely to be labor-saving, which allows using less labor to produce equal amounts of output.

In Chapter 11, Yong-seong Kim examines the intragenerational income mobility of Korea since 2000 and links it with income inequality. He begins with a comprehensive literature review. While studies on income mobility are growing in number in the West, in Korea they are at an early stage, in part because a dataset is still being developed. The author emphasizes that the financial crisis in 1997-98 dramatically altered the course of the Korean economy: income inequality soared suddenly, and then continued to rise, and consequently the gap between the haves and the have-nots widened. These trends in inequality portend a serious potential problem in income mobility. This is a motivation for the study, which examines the trends in intragenerational income mobility.

The main findings of the chapter suggest that rising income inequality observed since 2000 seems to be driven by an increase in within-group inequality, particularly for the less educated. By contrast, within-group inequalities among the more educated remain relatively stable over time. In particular, examination of the transition process based on relative income positions over time reveals that the direction of income mobility is negative for those who changed income positions.

In addition, a decomposition approach shows that income inequality is due primarily to the permanent component of income. When total variance of income is decomposed into its components, the share of variance 
of the permanent component increases over time and becomes dominant. This observation implies that a substantial part of income inequality has a persistent element, making it harder for income to be mobile. Limited income mobility of the less educated, together with the widening income gap, Kim argues, may make income polarization more serious. 